\title{
Do as the Swedes do? Internet policy and regulation in Sweden - a snapshot
}

\author{
Merlin Münch \\ Alexander von Humboldt Institute for Internet and Society, Berlin, Germany
}

Published on 10 May 2013 | DOI: 10.14763/2013.2.127

\begin{abstract}
When it comes to information technology Sweden is considered to be at the forefront both in terms of technological innovation, as well as in progressive policy-making, regulation and internet freedom. This article investigates the state-of-affairs in a number of fields of Swedish internet policy, such as copyright, net neutrality and censorship, in order to find out if and why the 'Swedish way' has been particularly efficient. In the course of this article it will become apparent that Swedens approach to internet policy and regulation has often been controversial, as the examples of the contested National Defence Radio Establishment law (known as the 'FRA-law'), as well as the rigorous implementation of the Directive on the enforcement of intellectual property rights have shown. Also, when it comes to matters of transparency, the Swedish government has some catching up to do.
\end{abstract}

Keywords: Sweden, Surveillance, Copyright, E-government, Internet policy

\section{Article information}

Received: 30 Apr 2013 Reviewed: 07 May 2013 Published: 10 May 2013

Licence: Creative Commons Attribution 3.0 Germany

Competing interests: The author has declared that no competing interests exist that have influenced the text.

URL:

http://policyreview.info/articles/analysis/do-swedes-do-internet-policy-and-regulation-sweden-snapsh ot

Citation: Münch, M. (2013). Do as the Swedes do? Internet policy and regulation in Sweden - a snapshot. Internet Policy Review, 2(2). https://doi.org/10.14763/2013.2.127

\section{LEADING THE PACK}

When it comes to information technology Sweden is considered to be at the forefront both in terms of technological innovation, as well as in progressive policy-making, regulation and internet freedom. In the World Wide Web Foundation's 2012 Web Index, Sweden ranked first among 61 nations, as the nation where the internet has the most significant political, social and economical impact. There seems to be something about the 'Swedish-way' that sets the country apart from many of its EU confederates. 
Nonetheless, as a member of the EU, Sweden too needs to commit to the implementation of certain EU-wide regulatory directives. Such directives, although uniform in their formulation, are subject to interpretation and local appropriation.

Surprisingly, as it may seem, Sweden's interpretation of the directive on intellectual property rights enforcement (IPRED), has exceeded the directives' scope to an extent that has caused critics to bemoan a curtailment of privacy rights. Similarly, in early 2009 passing of the socalled FRA-law - a legal measure sanctioning the surveillance of internet traffic content by state authorities - stirred considerable controversy as the law goes beyond the scope of surveillance established by the European Commission. As a result, some NGOs went as far as bringing the case before the European Court of Human Rights for human rights violations.

It seems that from a policy perspective Sweden is an interesting example, as it is both perceived as free and neutral, while at the same time pursuing a tough and much contested policy approach. The following 'snapshot' seeks to give a brief, yet nuanced picture of the Swedish policy landscape. With its outlook section, this article will also consider Sweden's role as an increasingly important stakeholder in EU and international policy-decisions, as well as the desirability of emulating the legal framework that governs the Swedish ICT-landscape in other national contexts.

\section{CONNECTING PEOPLE}

The most fundamental precondition for a vibrant internet culture, and consequently a vibrant discourse about internet policy, is access. In Sweden political intervention played a crucial role in creating a fertile ground for the development of a reliable and fast network-infrastructure as well as a stable, yet flexible legal framework to support it. Municipalities were offered subsidies for a faster development of their ICT infrastructure, in particular as an incentive for smaller communities to be able to offer high-speed connections to their residents (Olsson, 2006). Thus, whereas only $2 \%$ of all Swedes were connected to the internet in 1995 , by $201289 \%$ of the population enjoyed broadband access. (Findahl, 2012) The most significant increase can be observed in the use of mobile connections, with an almost twofold rise from 30 to 55 percent between the years 2011 and 2012. (Findahl, 2012) Regulatory provisions met by the government in order to promote competition among Internet Service Providers (ISPs) in particular helped to ensure shared access to web-infrastructure and to keep prices below the European average. 1

\section{ALL BITS ARE CREATED EQUAL - ISSUES OF NET NEUTRALITY}

In terms of net neutrality - the principle that internet service providers should treat all online content equally and not prioritise one application, platform, service user, etc. over another there is no legal obligation for ISPs to be 'network neutral'. Given the competitive nature of the market however, most providers declare to stick to a 'network-neutral' approach. (Geens, 2012) There are exceptions nonetheless. In their report on the state of net neutrality, the Internet Infrastructure Foundation (.SE) found that providers systematically give traffic with for instance Bittorrent file sharing protocols a lower priority. Moreover, contributing researcher at .SE Jörgen Eriksson argues, it is interesting to observe that it is extremely difficult, if at all possible, to gain an insight into what kind of content providers choose to block or prioritise.2 
Internet and telecommunications provider TeliaSonera for instance was heavily criticised by net neutrality activists and customers alike, following a statement made by the company in early 2012, in which it announced that it was considering starting to charge customers for the use of voice over IP services, such as Skype, or to simply block access to Skype and similar services, as they deemed VoIP to be harmful to their own business model. Due to heavy opposition, the company backed down from its plans later the same year, instead announcing two separate mobile plans for the future, leaving customers to choose between a pricier high-traffic and a somewhat cheaper low-traffic connection plan[ix].

\section{COPYRIGHT - OF PIRATES AND PIONEERS}

Intellectual property and copyright rank high among the most passionately debated policy domains at the time. As the birthplace of the most notorious file-sharing platform, The Pirate Bay, and the first pro file-sharing 'Pirate party', Sweden is certainly at the heart of the debate. In principle, file sharing has always been illegal in Sweden, however offenders had little to fear as there were insufficient means for prosecutors to identify alleged file-sharers. Some have therefore argued that, "The absence of functioning legal tools, surveillance and sanctions has contributed to the development within society of a large measure of acceptance of this type of crime, and, quite simply, people have not taken the law seriously" (Larsson \& Svensson, 2010). Thus for a long time, strong social norms encouraging infringement and lacking means to monitor illegal file-sharing meant that downloading and sharing copyrighted material was common practice, in particular among younger Swedes. (Larsson \& Svensson, 2010) Some authors even see the file sharing phenomena as the continuation of a particular Swedish 'against-the-grain' tradition. Jonas Andersson, in his article on the origins and impacts of Swedish file-sharing, places the phenomenon within a wider frame of more general shifts towards self-governance, individualisation and personal autonomy, notions that have a particularly strong tradition in late Swedish modernity (Andersson, 2013).

In 2009, in an effort to strengthen the position of right holders, Swedish parliament was the first in Europe to pass a law implementing the intellectual property rights directive (IPRED), previously passed by the European Parliament.3 The most significant and with no doubt most controversial change, that the implementation of the directive brought about was that it compelled ISPs to release the identity of alleged offenders. (Larsson \& Svensson, 2010; Geens, 2012) Users loudly objected and ISPs immediately challenged the new law before the Swedish Supreme Court. The court referred the decision on to the European Court of Justice, which in turn decided in a preliminary ruling in late 2012, that member states can indeed enact "legislation that makes it possible for ISPs to be requested to hand over subscriber information whose IP addresses have allegedly been used for intellectual property infringing purposes" 4 . In its ensuing verdict, the Swedish Supreme Court determined that "under current Swedish law rights holders can legitimately request the identifying information from the ISP" ${ }_{5}$. Public discontent with the implementation of the directive was strong enough to help the Pirate party win their first two chairs in European Parliament the elections. (Larsson \& Svensson, 2010; Geens, 2012)

Whereas file-sharing rates initially dropped after the implementation of IPRED, at the same time there was a rather significant surge in services offering anonymity online, such as VPNconnections, causing some to argue that there need to be stronger efforts to change the social norms that justify file-sharing, instead of getting tougher on legislation. (Larsson \& Svensson, 2010) Nonetheless, legislative measures following the implementation of IPRED likely 
incentivised the development of alternatives, such as music-streaming giant Spotify, or the video-on-demand service Voddler. In 2011, two out of three people in Sweden listened to music online, incidentally the same year that Spotify was officially launched. Interestingly, in 2012 the record industry saw its most profitable year since 2005, with $63 \%$ of all music purchases happening online $-90 \%$ of which came from streaming services. (Billing, 2013) It would be a bit too simplistic to establish a direct cause and effect relationship between the implementation of IPRED and the turn to and, indeed, success of legal alternatives. In particular considering the fact that downloading rates have again experienced a significant surge, reaching an all time high only months after the initial 'IPRED-scare'. Nonetheless, the existence of alternatives such as Spotify has given legal alternatives a considerable boost, leading some to expect a potential normative shift among users in favour of such alternatives (Billing, 2013).

\section{PRIVACY, SURVEILLANCE \& CENSORSHIP}

In the wake of the implementation of IPRED, the Swedish government in addition passed a legislative package that would grant the National Defense Radio Establishment (Försvarets Radio Anstalt - FRA) extensive surveillance power over online activities, in an effort to combat 'external threats' 6 . In effect, the laws invest the national defense intelligence agency with the authority and ability to monitor all cross-border cable-based communication (phone-calls, emails and other internet traffic, etc.) without a warrant - including the traffic's content - far exceeding the scope of surveillance allowed within the EU $\mathrm{U}_{5}$ NGOs, such as the Swedish Justice Centre (Centrum För Rättvisa - CFR) and the Norwegian division of the International Commission of Jurists (ICJ), have therefore argued that the law violates Article 8 and Article 13 of the European Convention on Human Rights, as well as article 12 of the Universal Declaration on Human Rights, which guarantee citizens the right to privacy and their ability to hold authorities accountable for potential human rights violations. (Landes, 2009)

Similarly, a centralised block-list has been the object of controversy. The list is issued by the authorities and subsequently implemented by ISPs by means of an automated DNS-filter, above all with the intent to block access to sites hosting child pornography. Critics, such as internet researcher Marcin de Kaminski from the Sociology of Law department at Lund University, however bemoan that maintenance of the list is not at all transparent and that there is no thirdparty control of the lists content. Neither is there a way to legally appeal a list entry. (Geens, 2012) Amongst other things this means that the selection of sites listed may be arbitrary in some instances and that without further checks and balances the list may become a political play-ball. In particular if a similar system would be emulated in countries with a higher extent of corruption and less trust in state authorities than in Sweden, where corruption levels are negligible and trust in the police is relatively high. An example of the potential arbitrariness of the block-list is the censoring of Finnish web-activist Matti Nikki's homepage, lapsiporno.info, on which the author ironically criticised the move towards more censorship.7

\section{AT THE FOREFRONT IN E-GOVERNMENT BUT NO OPEN DATA POLICY}

The problem of transparency similarly extends to the political sphere. Whereas Sweden was one of the first countries to offer e-government services like online tax-forms, as well as eidentification and various other e-services, government itself has not been at all as eager to 
make public data sets available. This is particularly interesting against the background of the socalled 'Principle of Publicity', an integral part of the Swedish constitution passed in 1766, which decrees that the general public, as well as the mass media, should "be guaranteed an unimpeded view of activities pursued by the government and local authorities". Accordingly, Sweden is the only Scandinavian country that does not have a national open data portal. In the list of 'open government' countries Sweden is still lagging behind considerably[xxv].

\section{OUTLOOK}

Sweden is often heralded as a role model for progressive policy-making, regulation and internet freedom. Governmental intervention and support for an early and swift development of an extensive and fast ICT infrastructure likely contributed to a solid basis for a vivacious internet culture - politically, socially and economically. However, as taking a closer look at some controversial policy-decisions such as the implementation of IPRED and the passing of the FRA-law has shown, Sweden's dealing with regulation is not entirely unproblematic, leaving the country's liberal image with a scratch. Likewise in matters of transparency there is some catching-up to do for the Swedish government.

As Sweden certainly also has an influence on EU policy-making8, it is necessary to consider in how far certain policy-decisions can only work in a particular Swedish context. Continuing on this thought consequently begs the question of how far policy decisions always need to be considered within a particular constitutional context. As the example of the block list suggests, certain institutional settings as well as trust in public institutions and a culture of free expression are preconditions to prevent the misuse of such policy implements for political, or other purposes.

One of Sweden's greatest assets, in the end, seems to be its vibrant culture of discussion and debate about internet policy and regulation - a culture that may to an important extent have grown out of a strong opposition to what was perceived as bad policy-making. As the country actively seeks to consolidate its role as an important stakeholder and initiator in global internet policy formulation processes, it will increasingly have to reflect on how policy decisions made at home potentially reverberate in the international community.

\section{FOOTNOTES}

1. See http://www.oecd.org/sti/broadband/39574970.xls

2. See Internetstiftelsen i Sverige, .SE:s rapport om nätneutralitet visar att vissa operatörer prioriterar ner trafik

3. See https://opennet.net/research/regions/nordic-countries

4. ECJ Bonnier Audio Aftermath: Swedish Supreme Court orders ISPs to reveal identity copyright infringers, retrieved April 15th, 2013, from

http://www.futureofcopyright.com/home/blog-post/2013/o1/o7/ecj-bonnier-audio-aftermathswedish-supreme-court-orders-isps-to-reveal-identity-copyrightinfring.html?no_cache $=1 \& \mathrm{cHash}=3 \mathrm{e} 53 \mathrm{ed} 27 \mathrm{c} 2 \mathrm{~d} 3 \mathrm{f} 8 \mathrm{ob} 8 \mathrm{f} 4 \mathrm{f} 307 \mathrm{~d} 64 \mathrm{boefa7}$

5. a. b. ibid. 
6. https://opennet.net/research/regions/europe, see; section on surveillance

7. See http://www.effi.org/julkaisut/tiedotteet/lehdistotiedote-2008-02-12-en.html

8. See

http://ec.europa.eu/dgs/home-affairs/what-we-do/policies/police-cooperation/swedish-initiati ve/index_en.htm 


\section{REFERENCES}

Billing, S. (2013). Swedes prefer streaming to downloading. The Local. Retrieved 23 April, 2013, from http://www.thelocal.se/46646/20130310/\#.UXok5L933dl

Findahl, O. (2012). Swedes and the Internet, iis.se. Retrieved 29 March, 2013, from https://www.iis.se/docs/Swedes-and-the-Internet-2012.pdf

Geens, S. (2012). Internet Freedom in Sweden - a Primer. Retrieved 29 March, 2013, from http://dliberation.org/2012/o4/13/internet-freedom-in-sweden-a-primer/

Larsson, S. \& Svensson, M. (2010). Compliance or Obscurity? Online Anonymity as a Consequence of Fighting Unauthorized File sharing. Policy \& Internet, 2(4), p.77-105.

Landes, D. (2009). Norwegian group joins case against Sweden's wiretapping law. The Local. Retrieved 24 April, 2013, from http://www.thelocal.se/17578/20090213/\#.UXuo6L933dk

Olsson, T. (2006). Appropriating civic information and communication technology: a critical study of Swedish ICT policy visions. New Media \& Society, 8(4), pp.611-627. 